\title{
Teoría y práctica de los derechos ancestrales de agua de las comunidades atacameñas
}

Manuel Cuadra L.

\section{RESUMEN}

Desde los albores del siglo XX, la principal causa de la pérdida de las aguas de las comunidades aymaras y atacameñas del norte de Chile, fue la desprotección jurídica en que éstas quedaron como consecuencia de la subordinación del derecho consuetudinario indígena al derecho positivo estatal, en un escenario de creciente demanda de esos recursos para abastecer a los centros mineros y las ciudades de la zona. Esta situación cambió, a lo menos en parte, con la dictación de la Ley $\mathrm{N}^{\circ} 19.253$ de 1993, más conocida como Ley Indígena, que reconoció los derechos de agua de propiedad ancestral de las comunidades aymaras y atacameñas, permitiendo su regularización. En la primera parte de este trabajo, me referiré al aludido conflicto entre derecho indígena y derecho estatal, y luego analizaré las implicancias del reconocimiento legal de aquellos derechos ancestrales. En la segunda parte, expondré algunos aspectos del primer programa de regularización de los derechos de agua de las comunidades atacameñas, cuya ejecución me encargó la Corporación Nacional de Desarrollo Indígena (CONADI), entre los años 1994 y 1999.

\section{ABSTRACT \\ Since the beginning of the twentieth century, the principal cause of water loss from the Aymaras and Atacameñas communities of the north of Chile, has been juridical deregulation. The juridical deregulation is a consequence of the subordination of the customary indigene right to the positive state right, in a scenario of increasing demand of this resource from miner's centers and the cities of the zone. This situation changed, at least in part, with the dictation of the Law $\mathrm{N}^{\circ} 19.253$ in 1993, known as the Indigene Law, which recognized the water}

1 Consultor CONADI, San Pedro de Atacama, II Región. Email: manuelcuadra@yahoo.es rights as ancestral property of the aymaras and atacameñas communities, allowing their regularization. The first part of my work is referred to the conflict between indigene rights and estatal rights, and to the implication of the legal recognition of the water's ancestral rights. In the second part, you will find aspects of the first regularization program of water rights of atacameñas communities, whose execution was entrusted to me by the National Corporation of Indigene Development, between the years 1994 and 1999.

\section{Introducción}

Para las comunidades aymaras y atacameñas del área andina del norte de Chile, el agua es un elemento de vida esencial. En torno al desierto de Atacama, uno de los más áridos y absolutos del planeta, siempre han utilizado este recurso de dos maneras distintas, pero complementarias: para riego agrícola, con los escasos ríos que descienden de la cordillera, y para el pastoreo de sus ganados en zonas de "vegas y bofedales", cuya existencia se debe al afloramiento natural de aguas subterráneas en el altiplano.

En ambos casos, estas comunidades han sufrido una permanente restricción de sus recursos hídricos. A la histórica escasez de agua por las condiciones propias de un clima desértico, se ha sumado en las últimas décadas una creciente demanda de este recurso para abastecer a las ciudades y los centros mineros de la zona, lo que ha comprometido incluso la sobrevivencia misma de dichas comunidades.

En efecto, la concesión de derechos a empresas mineras y sanitarias, tanto en aguas superficiales como subterráneas, además de privar a las comunidades de recursos vitales para su subsistencia, sin pago de indemnización alguna, ha causado graves deterioros a la biodiversidad de algunas cuencas, cuyas aguas han sido extraídas completamente. Ello desencadenó un proceso de abandono de la zona 
andina y de emigración de la población indígena hacia las ciudades, incrementando los sectores de mayor pobreza y marginalidad urbana.

A principios de la década de 1990, el Estado consideró que esta situación no podía persistir y que era necesario legislar al respecto. Así, se dictaron dos cuerpos legales de vital importancia para la protección de las comunidades indígenas del norte de Chile y de sus recursos hídricos:

- La Ley No 19.145 de 1992, que modificó el Código de Aguas para limitar la exploración y explotación de aguas subterráneas en zonas acuíferas que alimentan vegas y bofedales de las I y II Regiones del país.

- La Ley $N^{\circ} 19.253$, sobre protección, fomento y desarrollo de los indígenas de Chile, más conocida como Ley Indígena.

En este trabajo me referiré específicamente a un aspecto de este último texto legal, consistente en el reconocimiento de los derechos de agua de propiedad ancestral de las comunidades aymaras y atacameñas, contenido en el inciso $2^{\circ}$ de su artículo $3^{\circ}$ transitorio. Esta disposición ordena a la Corporación Nacional de Desarrollo Indígena (CONADI), y a la Dirección General de Aguas (DGA), establecer un convenio precisamente para la protección, constitución y restablecimiento de esos derechos.

Aunque las disposiciones permanentes de la Ley Indígena también se refieren a las aguas de las comunidades aymaras y atacameñas, especialmente el Art. 64, es indudable que el aludido precepto --pese a ser una disposición transitoria-- constituye el avance legislativo de mayor trascendencia en esta materia, pues consagra el expreso reconocimiento legal a los derechos consuetudinarios de aguas de estas comunidades, elevándolos a la categoría de "derechos ancestrales".

En la primera parte de este trabajo, intentaré aproximarme --desde la perspectiva de las comunidades atacameñas-- al conocimiento de las causas, contenido y efectos de aquel importante reconocimiento legal. En la segunda parte, procuraré cumplir con un deber que considero ineludible, cual es compartir algunos conocimientos y experiencias que adquirí en mi trabajo como coordinador del primer programa de regularización de los derechos de agua de las comunidades atacameñas, que por encargo de CONADI llevé a cabo entre los años 1994 y 1999.

\section{El Reconocimiento de los Derechos Ancestrales}

Conflicto entre derecho indígena y derecho estatal

Desde los albores del siglo $\mathrm{XX}$, las áridas regiones del norte de Chile han sido esenario de una verdadera disputa por sus recursos hídricos. En ella se han enfrentado, básicamente, dos realidades sociales, económicas y culturales contrapuestas: por un lado, el mundo rural y agrario de las comunidades indígenas del área andina y, por otro, el mundo urbano e industrial de las ciudades costeras y de la gran minería.

Esta disputa puso de manifiesto una controversia jurídica latente en casi toda América Latina: la confrontación entre el derecho consuetudinario y colectivista de los pueblos indígenas y el derecho positivo del estado-nación, generalmente individualista y de corte liberal.

La posición subordinada de un sistema normativo a otro ha sido una constante histórica. A lo largo del siglo XX, en la zona de estudio, ello se manifestó, en primer lugar, mediante la falta de reconocimiento legal de los usos consuetudinarios de agua de las comunidades indígenas, quienes por carecer de títulos o conseciones oficiales, fueron consideradas simples usuarios, de facto y al margen de la ley. En segundo lugar, se manifestó mediante la marginación de las comunidades indígenas de los procesos de regularización de derechos agua. Pese a la conveniencia de realizar estos trámites, a fin de obtener títulos, las comunidades no pudieron o simplemente no quisieron hacerlo, dada la complejidad de los procedimientos legales o la desconfianza que les producía el sistema oficial de derechos de agua, ciertamente muy ajeno a sus costumbres ancestrales.

Esta subordicación trajo como consecuencia que las aguas usadas por las comunidades indígenas quedaran en la más absoluta desprotección jurídica. Esta situación se acentuó todavía más a partir de la vigencia del Código de Aguas de 1981, que desvinculó la tierra del agua e impuso un sistema de propiedad privada de derechos de aprovechamiento, orientado al libre mercado y a la inversión empresarial, con mínimas restricciones a la explotación de los recursos hídricos (Castro 1997: 1). 
a) Uso de aguas sin títulos. De frente a un sistema oficial que pregona que el simple uso de aguas no otorga derecho alguno, sancionando toda extración que no haya sido previamente autorizada, para los atacameños, en cambio, el uso consuetudinario de las aguas, hecho con libertad y sin concesiones especiales, pero a vista y paciencia de la autoridad, avala plenamente su condición de legítimos usuarios de aguas, por derecho ancestral.

Portadoras de una cultura hadráulica de sorprendente tecnología, adecuada a la aridez del medio, para estas comunidades el agua es uno de los fundamentos principales de su existencia y cultura, al punto de ser catalogadas de "sociedades hidráulicas" (Pourrut 1995).

Sin embargo, esta especial vinculación con el recurso hídrico no es una característica propia de los atacameños, sino que constituye un rasgo común de prácticamente todas las sociedades andinas. Se ha dicho que en ninguna otra parte del mundo se ha prestado tanta atención a las aguas ni se las ha empleado con mayor éxito, como en el área andina. La construcción de terrazas de cultivo y el diseño de ingeniosas obras hidráulicas para captar y distribuir este recurso, fueron prácticas generalizadas, desde mucho antes de la llegada del conquistador español (Desmarchelier 1998).

Tanto fue así, que el soberano europeo mantuvo el orden que tenían los indios en la repartición de sus aguas. El mismo Emperador Carlos V, mediante real disposición de fecha 20 de noviembre de 1536, incorporada en la Recopilación de Indias de 1680, dispuso expresamente lo siguiente:

"Que el orden en que los indios tuvieren la división de sus tierras y partición de las aguas, aquella misma se guarde y practique entre los españoles en quienes tuvieren repartidas y señaladas las dichas tierras. Y que para ello sean señalados los mismos naturales que de antes tenían cargo dello, con cuyo parecer las dichas tierras sean regadas y se dé al agua debida sucesivamente de uno en otro, so pena que el que se quisiere preferir y por su propia autoridad tomar y ocupar el agua, le sea quitada hasta en tanto que todos los inferiores de él rieguen las tierras que así tuvieren señaladas" (Recopilación de Indias 4.17.11, cit. por Barrientos y Dougnac 1993: 127).
Pero si la Corona española tuvo el acierto de reconocer el derecho de los indígenas en sus tierras y aguas, adquirido según sus usos y costumbres, (Dougnac 1975: 440), no ocurrió lo mismo con las florecientes repúblicas independientes (Cuneo Vidal 1977: 98). En términos generales, las sucesivas legislaciones de aguas dictadas a partir del Código Civil de 1857, establecieron que todo uso de las aguas por los privados necesariamente debía ser autorizado por el Estado. Este otorga a los particulares una "concesión o merced de aguas", de la cual nacen "derechos de aprovechamiento de aguas". Así ha sido la regla general: no debieran existir usos válidos sin previa concesión (Vergara 1997: 5).

Desde los albores del siglo XX, el desarrollo de las ciudades costeras y de la gran minería del cobre en el norte de Chile, ligada a capitales extranjeros, comenzó a ejercer una fuerte presión sobre los recursos hídricos de la región, situados principalmente en el área andina. Como los agricultores y pastores atacameños no contaban con títulos o "papeles" que exhibir, en teoría eran simples usuarios de esas aguas, al margen de toda protección legal, de tal manera que estos recursos estaban virtualmente disponibles para ser concedidos a terceros.

Lo anterior, sumado a una política estatal centrada en el fomento de la minería y de la industria ${ }^{2}$, actividades asociadas a los centros urbanos de la costa, justificó la constitución de derechos de aprovechamiento a favor de empresas mineras y sanitarias en aguas usadas ancestralmente por los atacameños, sin reconocerles a éstos derecho alguno.

Las concesiones se centraron en los principales ríos de la cuenca del Loa. Primero fueron las aguas de la subcuenca de los ríos San Pedro e Inacaliri, otorgadas al Mineral de Chuquicamata y al Ferrocarril de Antofagasta a Bolivia. Luego fueron los principales afluentes de la subcuenca del río Salado, ríos Linzor, Hojalar, Toconce y Salado, concedidas al Mineral de Chuquicamata y a la sanitaria estatal Sendos, hoy Essan S.A. Más tarde, se entregaron las aguas del mismo río Loa, también a favor de Mineral de Chuquicamata, de la sanitaria Sendos, y de otras empresas.

\footnotetext{
2 Reglamento relativo a las mercedes que se soliciten en el río Loa y sus afluentes y en las aguadas y vertientes del de la Provincia de Antofagasta, de 30.10.1913, modificado por Decreto $\mathrm{N}^{\circ} 648$ de 26.03.1920.
} 
Así, los atacameños fueron paulatinamente privados de importantes recursos hídricos que usaban desde tiempos inmemoriales, sin recibir nada a cambio, a pesar del evidente perjuicio que ello les ocasionaba. En ciertos casos hubo derechamente despojo, como sucedió con la comunidad de Toconce, que me atrevo a catalogar como un caso "emblemático". En las aguas del río Toconce --en cuya quebrada la comunidad levantó su poblado y construyó la mayor extensión de terrazas de cultivos de toda la zona atacameña--, tanto el acto material de extraer y llevarse el recurso, como el acto jurídico de constituir las mercedes o derechos de aprovechamiento, lo ejecutó directamente el Estado a favor de una empresa de su propiedad ${ }^{3}$, sin consulta ni acuerdo de la comunidad y sin pago indemnización alguna.

b) Marginación de los proceso oficiales de regularización. La segunda forma como se manifestó este conflicto entre derecho indígena y derecho positivo, fue la marginación de las comunidades atacameñas de los procesos de regularización de derechos de agua, persistiendo en el tiempo su situación de simples usuarias, sín títulos. Aunque era indudable la conveniencia de realizar estos trámites, las comunidades no pudieron o no quisieron hacerlo, ya sea por la dificultad que les significaba acceder a los complejos procedimientos legales, o bien por la desconfianza que les producía la aplicación del sistema oficial de derechos de agua, que modificaba sustancialmente su forma tradicional de relacionarse no sólo con las aguas, sino con todo el medio ambiente.

En efecto, la concepción indígena de la tierra y el agua no como cosas que puedan ser vendidas, sino como componentes escenciales del hábitat ancestral de la comunidad, susceptibles de ser conservados a perpetuidad, ha estado en abierta contraposición con los sistemas legales imperantes, que han considerado a las aguas como un recurso económico más. No obstante ser estos bienes nacionales de uso público, se otorgan por la autoridad a los particulares mediante el denominado derecho de aprovechamiento, derecho real que es de dominio de su titular, facultándolo para usar, gozar y disponer libremente de las aguas, o para enajenar el derecho, con absolutamente independencia de la tierra.

3 La sanitaria Sendos, hoy Essan S.A.
En tal sentido, si el antiguo régimen español respetó la forma de propiedad colectiva y comunal que halló en uso entre los indígenas, ello no ocurrió bajo el régimen repúblicano: entre lo comunitario de tiempos remotos y lo individual de tiempos presentes, se labró un verdadero abismo (Cuneo Vidal 1977: 98). Desde la dictación del Código Civil, el derecho común ha tratado de incorporar las tierras y aguas indígenas al régimen de propiedad privada, fundamentalmente individual e inscrita.

Por de pronto, las leyes desconocieron a la comunidad como organización susceptible de ser propietaria de derechos de aprovechamiento, estableciendo que las solicitudes debían ser formuladas por un conjunto de personas individuales, con nombre y apellido, y no a nombre de la comunidad propiamente tal. Luego, cada comunero quedaba facultado para enajenar libremente su derecho o trasladar su ejercicio fuera de la comunidad, posibilitando así su adquisición por terceros extraños que podían llevarse las aguas a otro lugar de la cuenca.

Así las cosas, aunque en teoría era conveniente para los atacameños regularizar sus usos de aguas, en la práctica esto podía ser todavía más perjudicial para ellos, poniendo en peligro su sobrevivencia como pueblo y cultura.

Para comprender mejor estas ideas, resulta muy ilustrativo referirnos a la situación que se creó a principios de la década de 1990 en la zona atacameña, debido al rechazo por parte de las comunidades a la creación de comunidades de agua en su territorio, por parte de la DGA.

Desde la primera mitad de la década de 1980 , este servicio desarrolló programas de regularización de derechos de agua en distintos oasis agrícolas del norte de Chile, mediante la constitución de comunidades de agua, es decir, de organizaciones de usuarios establecidas en el Código de Aguas de 1981. Fruto de estos trabajos, el año 1984 se constituyeron varias de estas organizaciones en los oasis atacameños de Chiu-Chiu, Lasana y Calama.

Posteriormente, el año 1991, la DGA pretendió hacer lo propio en toda la zona atacameña, pero esta vez se encontró con la férrea oposición de los dirigentes indígenas. Según ellos, la aplicación del programa les impondría una forma de organización desconocida, que se apartaba por completo de sus cos- 
tumbres y que, en definitiva, desarticularía sus organizaciones comunitarias tradicionales.

Los aspectos más criticados del proyecto de la DGA fueron los siguientes:

- Se formarían comunidades de agua, es decir, organizaciones de usuarios que se limitan a administrar obras de regadío, pero que nada tienen que ver con la propiedad de los derechos de agua. Estos pertenecerían, en forma individual, a cada comunero, quien podría enajenarlo o gravarlo a su arbitrio; usar las aguas en lo que estimara conveniente o simplemente no usarlas; o bien trasladar el ejercicio del derecho fuera de la comunidad; todo ello con absoluta prescindencia del resto de los comuneros.

- Se constituirían comunidades de agua entre los usuarios de un mismo canal, o sea, existirían tantas comunidades como canales hubieran. Luego, como en todos los pueblos atacameños existen por lo general varios canales matrices que surten a su vez diversos canales secundarios, en cada uno de ellos existirían muchas comunidades de agua. Para los atacameños era inconcebible que al interior de sus comunidades se crearan otras organizaciones, independientes unas de otras, en las que el único vínculo entre sus integrantes fuera el hecho de captar las aguas a través de un mismo canal.

Dentro de las comunidades de agua, cada comunero tendría derecho a un voto por cada acción que poseyera. La asignación de estas acciones dependería, de acuerdo con la ley, del volumen de agua que corresponda a cada usuario en el caudal común, en términos que entre más agua se pueda extraer, correspondería un mayor número de acciones y, consecuentemente, más votos y mayor poder de decisión dentro de la organización.

Como puede apreciarse, todos estos aspectos repugnan con la organización colectivista de las comunidades andinas. Para ellas, las aguas son de las tierras que se riegan con ellas, lo que conforma una unidad territorial indivisible que es de propiedad corporativa del ayllu o comunidad indígena, siendo inconcebible la apropiación privada ni de las tierras ni de las aguas.

Es atendible, pues, que los atacameños no aceptaran la posibilidad que cada comunero fuera dueño de un derecho que pueda enajenar libremente; o que las aguas fueran administradas por diversas organizaciones, una por cada canal, al margen de la comunidad indígena; $\mathbf{o}$, en fin, que los comuneros tuvieran mayor o menor poder de decisión dependiendo del volumen de agua que utilicen.

$\mathrm{Al}$ respecto, ésta fue opinión dada entonces por el dirigente atacameño Manuel Escalante Pistán:

"Lo anteriormente expuesto, es gravisimo por cuanto se pone en riesgo la sobrevivencia misma de la cultura atacameña al incorporar conceptos totalmente desconocidos, transformándola e iniciando una carrera por la acumulación de derechos por parte de agentes foráneos con poder económico, ofreciendo sumas de dinero no manejadas en la actualidad por los agricultores, quienes deslumbrados por éste, acceden a la venta de sus aguas, solucionando problemas puntuales pero dejando a sus herederos sin la posibilidad de continuar con la actividad agrícola, viéndose obligados a emigrar a otros centros poblados" (Escalante 1992 Ms.).

En suma, la oposición generalizada de los atacameños a la aplicación del citado programa, fue tan tenaz y categórica, que la DGA tuvo que liquidar el contrato de ejecución del proyecto y destinar los fondos a otros fines.

En todo caso, conviene destacar que el tiempo demostró que los temores de los dirigentes atacameños fueron bastante acertados. En los últimos años han sido usuales las compras de derechos de agua a los miembros de las comunidades de agua de Calama, Chiu-Chiu y Lasana, principalmente por empresas mineras y la sanitaria estatal Essan S.A., seguidas de autorizaciones para trasladar el ejercicio de los derechos fuera de los canales de la comunidad. Así, las aguas de uso agrícola en dichos oasis son cada vez más escasas, especialmente en Calama, ocasionándose un grave impacto al equilibrio ecológico de los oasis y la paulatina desecación de amplias zonas agrícola cultivadas desde tiempos prehispánicos.

Las consecuencias de este proceso

La concesión de derechos de aprovechamiento a empresas mineras y sanitarias, tanto en aguas superficiales de uso agrícola como en aguas subterráneas que alimentan zonas de pastoreo, ha traido consecuencias negativas tanto para las comunidades 
atacameñas como para la sociedad en general.

Desde el punto de vista de las comunidades, además de la privación de recursos fundamentales para su subsistencia, sin pago de indemnización alguna, muchas de éstas, al perder el control sobre el agua, han perdido también uno de los núcleos de su cohesión. Hoy la comunidad de Toconce prácticamente sólo puede administrar la cuota que Essan S.A. le otorga. Los escasos habitantes del sector alto del río Loa, expresan con dolor lo que ha sido la pérdida de la comunidad para ellos: "cuando había unidad, había fuerza. Ahora nosotros ya perdimos". Por el contrario, aquellas comunidades como Caspana y Ayquina, en el sector del río Salado, y Socaire y Peine, en el salar de Atacama, que aún controlan sus fuentes de agua, muestran tener la capacidad de organizar a sus comuneros para la ejecución de trabajos colectivos, como la contrucción o reparación de canales de regadío, la apertura o reparación de caminos, etc. (Castro y Martínez 1996: 81).

Ahora, desde la perspectiva de la sociedad en general, se pueden mencionar las siguientes consecuencias según Aldunate (1985: 137).

- Despoblamiento y abandono de tierras agrícolas y zonas de pastoreo del área andina del norte de Chile, perdiéndose un valioso patrimonio tecnológico y cultural, que fue capaz de hacer habitable y productiva una área geográfica con fuertes restricciones para la vida humana y la actividad agropecuaria.

- Emigración de la población indígena desde sus pueblos originarios hacia las ciudades, engrosando los sectores de mayor pobreza y marginalidad urbana.

- Grave deterioro de la biodiversidad de algunas cuencas, cuyas aguas han sido completamente extraídas, sin respetarse un "caudal mínimo ecológico".

Sin embargo, pese a todos estos embates, los atacameños han seguido utilizando las aguas disponibles, en forma comunitaria, como siempre ha sido su costumbre. Los que todavía viven en sus pueblos y los que los visitan periódicamente desde las ciudades, principalmente de Calama, continúan regando sus cultivos y abrevando sus animales; organizan ceremonias de "limpia de canales" $y$, en fin, per- sisten en su intento por subsistir de acuerdo a sus patrones tradicionales de vida.

Esta tenacidad es, a fin de cuentas, la justificación misma de las normas legales dictadas para la protección, el fomento y el desarrollo de los indígenas de Chile, contenidas en la Ley $N^{\circ} 19.253$ de 1993. A través de ellas, nuestro odenamiento jurídico valora y ordena proteger lo que queda de esas formas tradicionales de vida en el desierto, cuyo fundamento es precisamente el uso comunitario de las aguas.

Como principal medida de protección, el legislador reconoce que estos usos son, ni más ni menos, "derechos ancestrales", sobre los cuales las comunidades indígenas tienen "propiedad", aunque no cuenten con títulos o concesiones de la autoridad. Estos derechos tienen plena validez y protección a partir de este reconocimiento legal, sin perjuicio de poder ser formalizados o regularizados posteriormente, aplicando los procedimientos que establece la ley.

De usuarias de aguas a dueñas de derechos ancestrales

Pues bien, la Ley Indígena --aprobada por la unanimidad del Congreso Nacional-- reconoció la existencia de las "comunidades indígenas" (Art. 9) como una realidad histórico-sociológica que se remonta incluso a tiempos precolombinos (Art. $1^{\circ}$ ), independientemente de su constitución legal (Art. 10). Creó la Corporación Nacional de Desarrollo Indígena (CONADI), servicio público encargado de aplicar esta ley y, en relación con las comunidades del norte, estableció importantes normas para la protección de sus aguas:

- Creó el Fondo de Tierras y Aguas Indígenas, administrado por CONADI, cuyo objetivo es, entre otros, financiar la constitución, regularización o compra de derechos de agua (Art. 20).

- Prohibió la enajenación y el gravamen de los derechos de agua que las comunidades hayan adquirido con recursos del Fondo de Tierras y Aguas Indígenas (Art. 22).

- Ordenó proteger especialmente las aguas de las comunidades aymaras y atacameñas (Art. 64).

Con todo, es en mi opinión el Art. $3^{\circ}$ transitorio, inciso $2^{\circ}$, del citado texto legal, el que contiene el 
precepto de mayor importancia en relación con la materia que nos ocupa, desde que admite expresamente la existencia de "derechos de agua de propiedad ancestral de las comunidades aymaras y atacameñas", ordenando a CONADI y la DGA establecer un convenio para su protección, constitución y restablecimiento. ${ }^{4}$

Esta norma, ciertamente, debe ser interpretada dentro del contexto del Art. 19, $\mathrm{N}^{\circ} 24$, inciso final, de la Constitución Política del Estado, que dispone: "Los derechos de los particulares sobre las aguas, reconocidos o constituidos en conformidad a la ley, otorgarán a su titulares la propiedad sobre ellos". Mediante esta norma, nuestro ordamiento constitucional otorgó reconocimiento jurídico y plena validez no sólo a los derechos de agua "constituidos" por acto de autoridad, sino que también a los usos consuetudinarios de agua, en cuanto se refiere a los "derechos reconocidos de acuerdo a la ley" (Vergara 1997: 8).

Luego, habiendo reconocido la Ley Indígena los derechos de agua de propiedad ancestral de las comunidades aymaras y atacameñas, éstos ocupan un lugar equivalente, en vigencia y protección, a los derechos "constituidos" por acto de autoridad.

Ello revierte, de alguna manera, la situación de subordinación del derecho consuetudinario indígena al derecho positivo estatal. Ciertamente, a través de la Ley Indígena el ordenamiento jurídico reconoció la legitimidad de los usos consuetudinarios de aguas de las comunidades aymaras y atacameñas, dándoles la categoría de derechos, de tal suerte que aunque estas comunidades carezcan de títulos concesionales otorgados por la autoridad, ya no son simples usuarias de aguas, de facto, al margen de la ley o como quiera llamárselas. Ahora, por el sólo ministerio de la ley, son dueñas ancestrales de derechos de agua "reconocidos de acuerdo a la ley".

Si bien hoy es un hecho innegable la existencia en nuestra legislación de derechos de agua consuetudinarios o de usos consuetudinarios de aguas reconocidos como derechos por la ley (Vergara 1998: 329), lo especial y novedoso del reconocimiento contenido en la Ley Indígena es que declara como propietarias de estos derechos a las "comunidades

4 El convenio se suscribió en la ciudad de Iquique, con fecha 30.05.97. indígenas", es decir, a entidades distintas de sus miembros individualmente considerados.

En otras palabras, la Ley Indígena reconoció "derechos consuetudinarios y colectivos de aguas", acorde con la concepción ayamara y atacameña en esta materia.

Aunque estos derechos no estén constituidos ni inscritos, no por ello adolecen de problemas de existencia, sino tan sólo de falta de formalización registral: es un derecho sobre el cual la "comunidad" tiene "propiedad" y, por eso, precisamente, es "reconocido"; sin embargo, para los efectos de su certeza, la misma ley contempla un sistema de regularización que, cumpliéndose con ciertos requisitos, permite su formalización registral.

Así, estos usos consuetudinarios de agua "reconocidos --como derechos-- de acuerdo a la ley", pueden optar por la "regularización" cuando reunen los requisitos de legitimidad que establece el Art. $2^{\circ}$ transitorio del Código de Aguas: uso ininterrumpido de las aguas, libre de violencia y clandestinidad y sin reconocer dominio ajeno.

Acreditándose estas circuntancias ante un Tribunal, procede que éste declare la regularización del derecho, mediante una sentencia judicial. La regularización es un acto meramente declarativo: constata la existencia del derecho pero no lo "constituye" ni crea originariamente. Le otorga certeza jurídica y, por ende, mayor protección, permitiendo además determinar sus características esenciales: caudal, punto de captación y si se trata de derechos consuntivos o no consuntivos; de ejercicio permanente o eventual; continuos, discontinuos o alternados, como los clasifica el Código de Aguas vigente.

Identificación y elementos de los derechos ancestrales

El reconocimiento legal de los derechos ancestrales es de carácter genérico, ya que la ley no determina en cada caso, en qué aguas se ejercen, a qué comunidad pertenecen, ni cuáles son sus características esenciales. Sin embargo, para nadie es novedad que la aplicación de una norma legal, abstracta y general, a un caso concreto y particular, es una cuestión de hecho que debe hacerse caso a caso, sobre la base de las descripciones genéricas contenidas en la ley. 
En la especie, tales descripciones están en el Art. $3^{\circ}$ transitorio, inciso $2^{\circ}$, de la Ley Indígena, que ordena a CONADI y a la DGA establecer un convenio para la protección, constitución y restablecimiento de los derechos de agua de propiedad ancestral de las comunidades atacameñas; en su Art. $1^{\circ}$ inciso $2^{\circ}$, cuando señala que una de las principales etnias indígenas de Chile es la de las comunidades atacameñas del norte del país; en su Art. $9^{\circ}$ letra 'd', que entiende por comunidad indígena toda agrupación de personas pertenecientes a una misma etnia indígena y que provengan de un mismo poblado antiguo; y en su Art. 62, cuando señala que son atacameños los indígenas pertenientes a las comunidades existentes principalmente en los poblados del interior de la II Región.

Como puede observarse, estas normas proporcionan los elementos básicos que permiten individualizar en la práctica cuáles son los derechos ancestrales. En primer lugar, las aguas en que éstos recaen deben encontrarse dentro de un determinado ámbito geográfico: el interior de la II Región; luego, debe existir uso ancestral o antiguo del recurso; $y$, finalmente, este uso debe ser realizado en forma colectiva por la "comunidad indígena" y no por meros regantes individuales, aunque también sean indígenas.

En tales condiciones, no cualquier uso de aguas es un derecho ancestral. El legislador impone algunas condiciones que restringen el ámbito de aplicación del reconocimiento de estos derechos. Para empezar, existe un límite espacial, puesto que los usos deben realizarse dentro de un espacio territorial y no en otro; en seguida, existe un límite temporal, ya que los usos deben ser antiguos y no recientes, ni menos posteriores a la Ley Indigena; $y$, finalmente, existe una límite de forma, pues los usos deben ser comunitarios y no individuales.

A continuación analizaremos cada uno de estos elementos:

a) Ambito geográfico de los derechos. Tal como advierte la ley, las comunidades atacameñas existen principalmente en los poblados antiguos del interior de la II Región. En consecuencia, las aguas que usan y, por ende, en las recaen sus derechos ancestrales, deben encontrarse dentro de ese ámbito geográfico y no en otro.
El interior de la II Región es, desde luego, el territorio en que tradicionalmente han habitado las comunidades atacameñas. Este se compone de dos sectores bien diferenciados: la cuenca del río Loa por el norte, actuales comunas de Ollagüe y Calama, y la cuenca del salar de Atacama por el sur, actual comuna de San Pedro de Atacama, ambas de la Provincia de El Loa.

Históricamente, el primer sector ha sido denominado Atacama La Baja, y comprende las comunidades de Chiu-Chiu, Lasana, Conchi, Ayquina, Cupo, Caspana y Toconce; mientras que el segundo, denominado Atacama La Alta o Atacama la Grande, comprende las comunidades de Machuca, Río Grande, San Pedro de Atacama --y de sus ayllus Quitor, Condeduque, Larache, Séquitor, Coyo y Solor, entre otros--, y siguiendo al sur, Toconao, Talabre, Camar. Socaire y Peine.

Ahora bien, dentro de este ámbito geográfico general, que abarca todo el territorio atacameño, pueden identificarse a su vez los territorios particulares de cada comunidad, en los que se encuentran sus respectivos derechos ancestrales. Estos territorios pueden ser determinados aplicando un mismo criterio, el "patrón de asentamiento" común para todas las comunidades atacameñas.

Aunque esta materia compete más bien a los antropólogos, me referiré muy suscintamente a ella, atendida su estrecha vinculación con el uso del recurso hídrico.

Dadas sus condiciones ambientales y climáticas, tipo desierto de altura, la zona atacameña se caracteriza por reunir las condiciones más estrictas de los Andes en cuanto a aridez y, por tanto, en cuanto a la reproducción de la flora y fauna. El aprovechamiento de este territorio siempre se ha realizado en forma de asentamientos de grupos de agropastores dispersos, discontinuos o "insulares" en torno a las fuentes de agua, rodeados de vastos territorios sin agua, llamados "despoblados" (Núñez 1992: 35).

Estas agrupaciones siempre se han organizado en comunidades, correspondiéndole a cada una de ellas un territorio específico. Cada territorio se articula en torno a un núcleo aldeano central --el poblado-y algunas localidades menores dependientes de él, situados en oasis fluviales de uso agrícola y ganadero. Por otro lado, existen las zonas de pastoreo, 
denominadas "estancias", que se encuentran por lo general en pisos ecológicos más altos y distantes, donde el afloramiento de aguas subterráneas permite la formación de vegas o pastos húmedos. Todo ello, pues, se traduce en una ocupación del espacio productivo muy dispersa y, por lo mismo, muy amplia (Castro y Martínez 1996: 76).

Desde su poblado, cada comunidad organiza la ocupación del espacio y el aprovechamiento de sus recursos productivos, proyectándose hasta las más lejanas estancias. Estos dos tipos de asentamiento --el poblado y la estancia-- son el fundamento de la estructura territorial de las comunidades atacameñas, y en ellos podemos encontrar las aguas de uso agrícola y pastoril sobre las cuales recaen sus derechos ancestrales.

Por consiguiente, cada comunidad es dueña de derechos antecestrales sobre las aguas que riegan sus tierras agrícolas y zonas pastoreo, pero no sobre aquellas que irrigan los cultivos y campos de pastoreo de otra comunidad. Como veremos más adelante, las propias comunidades han generado un sistema de normas consuetudinarias que asignan las aguas entre ellas, reconociéndose mutuamente el derecho a utilizar determinadas fuentes y a construir las respectivas obras de captación.

Como puede apreciarse, los derechos de agua de propiedad ancestral de las comunidades atacameñas, están vinculados a las tierras de cada una de ellas, en concordancia con la concepción andina del espacio como totalidad. Los atacameños no conciben a las aguas desvinculadas de las tierras que se riegan con ellas. Para ellos, ambos elementos conforman una unidad territorial indivisible: el hábitat ancestral del ayllu o comunidad indígena, donde ésta constantemente recrea su cultura e identidad. Consecuentemente, es inconcebible la apropiación privada ni de las tierras ni de las aguas, existiendo un derecho de uso común que se regula mediante normas consuetudinarias aceptadas por todos.

b) Uso consuetudinario de las aguas. Según la ley, las comunidades aymaras y atacameñas tienen propiedad "ancestral" sobre derechos de agua, vale decir, un derecho de origen remoto, heredado de sus ancestros o antepasados.

Esta ancestralidad no proviene, desde luego, de antiguos títulos otorgados por la autoridad a sus as- cendientes, los que en la zona atacameña nunca existieron. Proviene, más bien, del uso consuetudinario de las aguas, realizado desde tiempos inmemoriales.

Por lo tanto, para que opere el reconocimiento legal de los derechos ancestrales, debe existir uso antiguo del recurso hídrico, hecho con la convicción de que se trata de un uso legítimo y constitutivo de derecho.

Como acabamos de ver, el uso de las aguas por los atacameños siempre se ha realizado de dos maneras distintas, pero complementarias: para la agricultura, en oasis fluviales (poblados), para pastoreo, en zonas de vegas (estancias). Ambos usos tienen la misma importancia socioeconómica y cultural para las comunidades, pero es indudable que la agricultura evidencia más nítidamente la utilización sistemática y organizada del recurso hídrico a lo largo del tiempo, a través de la construcción y el manejo de obras hidráulicas.

En la zona atacameña, estas obras se remontan incluso a épocas prehispánicas, tal como lo demuestran evidencias existentes desde el río San Pedro de Inacaliri, por el norte, hasta la quebrada de Tilomonte, por el sur. En el sector norte (río Loa) son importantes las obras de las quebradas que desembocan en las vegas de Turi, especialmente la de Paniri, así como en las tierras de cultivo en torno al cerro Topaín. Existen represas, acueductos, canales tallados en rocas, canales realizados con anhidrita, como el canal que abastecía de agua al Pucara de Chiu-Chiu. En Caspana y Toconce se construyeron largos canales que hasta hoy se utilizan. En el sector sur (salar de Atacama), se encuentran vestigios de canalización y tierras de cultivo desde Río Grande y Puritama hasta Tarajne y Tilomonte, pasando por Zapar, Toconao, Soncor y Socaire (Núñez H. 1991: 201).

La construcción y el manejo de estas obras hace palmaria la utilización generalizada, constante y uniforme de las aguas a lo largo de los años, imponiendo a los usuarios la necesidad de generar por si mismos las normas que regulan esa utilización. Estas normas se crean y perfeccionan a partir de la experiencia, y van adquiriendo legitimidad y fuerza obligatoria en la medida que son aplicadas por los mismos usuarios.

Con todo, el riego no sólo ha tenido para los 
atacameños un notable valor funcional y económico, por el aumento de la productividad agrícola, sino que también un profundo sentido ritual y religioso, que refuerza la convicción de legítimidad del uso del recurso hídrico. Esto lo demuestra claramente la tradicional ceremonia de "limpia de canales", cuyo significado trasciende lo meramente funcional, pudiendo ser considerada una actividad simbólica de la comunidad (Matus de la P. 1993-94). La limpieza de los canales de regadío antes del período agrícola de cada año, hecha hasta hoy en forma comunitaria, envuelve una serie de ritos que evidencian un verdadero "culto al agua" (Núñez A. 1992: 235), insinuándonos como debió organizarse antiguamente el trabajo comunitario para realizar grandes obras hidráulicas y hacerlas funcionar con una producción óptima (Núñez H. 1991: 203).

c) Uso comunitario de las aguas. Según el Art. $3^{\circ}$ transitorio de la Ley $\mathrm{N}^{\circ} 19.253$, las propietarias ancestrales de los derechos de agua son las comunidades aymaras y atacameñas, es decir, entidades histórico-sociológicas distintas de sus miembros.

De acuerdo con el Art. 9 del mismo cuerpo legal, las comunidadas indígenas son agrupaciones de personas pertenecientes a una misma etnia indígena y que además, en el caso particular de las comunidades del norte, provienen de un mismo poblado antiguo, situación prevista en la letra 'd' de dicho artículo.

Estas normas legales simplemente reconocen una realidad: los atacameños siempre se han organizado en comunidades, bajo un patrón de asentamiento de tipo disperso que se articula en torno a un poblado. Sin la dualidad poblado-comunidad, sería muy difícil concebir la ocupación particular del espacio y el manejo de los recursos productivos en la zona atacameña, situada en uno de los desiertos más aridos y absolutos del planeta. Por lo demás, únicamante el trabajo comunitario puede explicar la existencia y operación de los complejos sistemas hidráulicos prehispánicos (Núñez H. 1990: 31).

La ley ha reconocido, entonces, derechos comunitarios o colectivos de agua, que nacen del uso consuetudinario de las aguas realizado por la comunidad indígena propiamente tal, y no por sus miembros individualmente considerados.

En suma, las aguas vinculadas a un territorio, como componentes inseparables del habitat ancestral de la comunidad; el uso consuetudinario de las aguas en agricultura y pastoreo, como instrumento fundamental del manejo de los recursos productivos de la zona; y la comunidad, como forma de organización socioeconómica de la población, constituyen los fundamentos de la particular forma de vida de los atacameños, que se manifiestan ya en la época prehispánica y que se mantienen, sin mayores variaciones, hasta nuestros días.

Estos son los elementos de los derechos ancestrales. La Ley $\mathrm{N}^{\circ} 19.253$ tuvo el acierto de reconocerlos, posibilitando así que las comunidades atacameñas puedan proteger y regularizar sus aguas, de acuerdo con sus propias costumbres.

Efectos del reconocimiento legal de los derechos ancestrales

Sobre la base de lo expuesto, podemos señalar que los efectos del reconocimento legal de los derechos ancestrales, son básicamente los siguientes:

La ley le otorgó legitimidad a los usos consuetudinarios de aguas de las comunidades aymaras y atacameñas. Los reconoció como derechos, situándolos en un lugar equivalente, en vigencia y protección, a los derechos constituidos por acto de autoridad.

Luego, aunque estas comunidades carezcan de títulos, ya no son simples usuarias de aguas, de facto o al margen de la ley, sino dueñas ancestrales de derechos de agua "reconocidos de acuerdo a la ley", en los términos del Art. 19, $\mathrm{N}^{\circ} 24$, inciso final, de la Carta Fundamental.

Sin embargo, no cualquier uso de aguas goza de reconocimiento legal, sino únicamente aquellos que cumplen con ciertas condiciones: deben recaer en aguas que se encuentren dentro del hábitat ancestral de las comunidades aymaras y atacameñas; deben ser usos antiguos; $y$, por último, deben ser usos colectivos y no individuales.

Estos usos --reconocidos como derechos-- pueden optar por la "regularización" o formalización registral, cuando reúnen los requisitos de legitimidad que establece el Art. $2^{\circ}$ transitorio del Código de Aguas: uso ininterrumpido de las aguas, libre de violencia y clandestinidad y sin reconocer dominio 
ajeno. La regularización simplemente otorga certeza jurídica a los derechos ancestrales, pero no los crea originariamente, ya que éstos existen por el sólo ministerio de la ley, a partir del reconocimiento contenido en ella.

Uno de los aspectos más trascendentales de este reconocimiento legal, es que a través de él, nuestro ordenamiento jurídico le otorgó validez a la costumbre indígena como fuente del derecho. En efecto, como los derechos ancestrales son comunitarios --pertenecen a la comunidad--, ningún comunero, individualmente considerado, es dueño de derecho alguno, de tal suerte que las relaciones entre ellos no se regulan por las normas sobre organizaciones de usuarios del Código de Aguas, las que se aplican sólo entre quienes tienen "derechos de aprovechamiento" en las aguas de un mismo canal o embalse. ${ }^{5}$ Dentro de la comunidad, rigen las normas consuetudinarias que libremente se dan los propios comuneros.

Como dijimos, la utilización generalizada de las aguas a lo largo de los años, en forma constante y uniforme, impuso a las comunidades la necesidad de generar por si mismas las normas que regulan esa utilización. Estas normas, que se crean, perfeccionan y legitiman a partir de su aplicación prácti$\mathrm{ca}$, tienen en la actualidad plena validez y fuerza obligatoria en el seno de cada comunidad.

En tal sentido, la consagración legal de estos derechos ancestrales, no sólo es importante porque reconoce el derecho consuetudinario vigente al interior de cada comunidad, sino que además, al establecer como fuente del derecho a la costumbre, permite a través de ésta, que se vaya reelaborando constantemente la norma jurídica. Dicho de otro modo, de cierta forma se le confirió a la comunidad indígena la facultad de legislar por si misma.

\section{La regularización de los Derechos Ancestrales}

Una de las primeras actividades de CONADI en la II Región, durante el segundo semestre del año 1994,

5 Según el Art. 186 del Código de Aguas, las organizaciones de usuarios --comunidades de agua, asociaciones de canalistas y juntas de vigilancia-- pueden formarse entre dos o más personas que tienen derechos de aprovechamiento en las aguas de un mismo canal o embalse, o usan en común la misma obra de captación de aguas subterráneas, con el objeto de reglamentar las consecuencias de este hecho. fue llamar a licitación privada para la ejecución del proyecto de regularización de los derechos de agua de las comunidades atacameñas. El programa, financiado con recursos del Fondo de Tierras y Aguas Indígenas, fue adjudicado a Cuadra \& Escalante Consultores y Cia., la que inició los trabajos en enero de 1995 y los concluyó a fines de 1999.

Mediante este proyecto se pretendió --y en gran medida se consiguió-- regularizar la mayoría de los derechos de agua de propiedad ancestral de las comunidades atacameñas, tanto de uso agrícola como pecuario. Para ello se invocaron y, en definitiva, se lograron aplicar, las normas legales sobre reconocimiento y protección de estos derechos ancestrales, analizadas en el capítulo anterior.

Considero de gran interés mencionar los aspectos más relevantes de este proyecto, atendida la enorme trascendencia que éste ha tenido para las comunidades atacameñas. Aparte de haber quedado todas estas legalmente constituidas, e inscritos a su nombre 70 derechos por un caudal superior a 2.270 litros por segundo, lo central de este trabajo, en mi opinión, fue haber obtenido una valiosa jurisprudencia judicial que reconoció, en el fondo, que las actuales comunidades aymaras y atacameñas, pese a tener personalidad jurídica sólo a partir de la Ley Indígena de 1993, son las continuadoras y legítimas herederas de aquellas que han habitado estos territorios desde tiempos inmemoriales, sin solución de continuidad, y que en tal carácter tienen perfecto a derecho a regularizar, hoy, los usos consuetudinarios de aguas iniciados por sus antepasados más remotos.

\section{Exigencias del proyecto}

Las bases de la licitación establecieron ciertas pautas básicas para la ejecución del proyecto, con el objeto de satisfacer los deseos y aspiraciones de las comunidades atacameñas con respecto a la regularización de sus derechos de agua:

- En primer lugar, atendida la convicción de los atacameños de ser dueños ancestrales de derechos de agua, se debía solicitar el reconocimiento judicial de estos derechos y no la concesión de nuevos derechos por la vía administrativa. Se debía aplicar, en consecuencia, el procedimiento de regularización del Art. $2^{\circ}$ transitorio del Código de Aguas, que permite inscribir derechos no 
inscritos, cuando el uso de las aguas tiene la antigüedad y las características que exige ese precepto. Se trata, en pocas palabras, de una regularización por el uso, la posesión o la prescripción adquisitiva de los derechos (Agurto 1986: 35).

Esta opción, además, tuvo un claro sentido práctico, desde que la alternativa de solicitar nuevos derechos implicaba asumir el riego cierto de sacar a remate estos derechos (Agurto 1986: 36). En efecto, conforme a lo dispuesto en el Art. 142 del Código de Aguas, si se solicita la constitución de derechos y dentro del plazo que fija la ley se presentan otras solicitudes sobre las mismas aguas, sin que exista disponibilidad para satisfacer todos los requerimientos, la DGA debe citar a un remate entre los solicitantes.

Así, pues, la alternativa de solicitar la "constitución" de los nuevos derechos, habría la posibilidad de provocar un gran remate, al mejor postor, de los derechos de agua de propiedad ancestral de las comunidades atacameñas, lo que resultaba absolutamente inadmisible.

Dado que los atacameños aprovechan las aguas en forma comunitaria, como siempre ha sido su uso y costumbre, los peticionarios de la regularización debían ser comunidades indígenas. Sólo si ello era imposible, las peticionarias podían ser asociaciones indígenas.

La idea era inscribir derechos "comunitarios", cuyos titulares fueran organizaciones indígenas distintas de sus miembros individualmente considerados.

- Como las comunidades indígenas atacameñas cuentan por lo general con dos o más fuentes de agua - -y en cada una de ellas con uno o más canales matrices de gran extensión y un alto número de canales secundarios (Castro 1997: 69)--, cada solicitud de regularización debía comprender todas las fuentes utilizadas por la respectiva comunidad, siendo absolutamente improcedente formar distintas organizaciones, por canal.

- Para los atacameños, sus derechos ancestrales se extienden desde el "nacimiento" de cada río o vertiente, hasta el último terreno regado. Esta es una noción propia de la concepción andina del espacio como totalidad (Castro 1997: 67), que entiende que las aguas son inseparables de las tierras que recorren y riegan.

Este criterio, sin embargo, no tiene asidero dentro de nuestro sistema legal vigente, que separa la tierra del agua y determina que los elementos esenciales del derecho de aprovechamiento son básicamente el caudal y el punto de captación, con absoluta prescindencia del lugar donde las aguas nacen o mueren.

En este contexto, se estimó que la única fórmula legal que permitiría, de algún modo, reservar para una comunidad indígena la totalidad de un río o vertiente, desde su nacimiento, era solicitando el máximo caudal posible, de tal manera de agotar la disponibilidad del recurso e impedir así, futuras concesiones de derechos a terceros.

En síntesis, mediante estas exigencias se pretendió dar viabilidad legal a la regularización de los usos consuetudinarios de aguas de las comunidades atacameñas, en orden a obtener el reconocimiento de "derechos ancestrales", que sean "comunitarios" y que protejan las aguas "desde sus nacimientos", tal como lo decían y recalcaban los propios dirigentes indígenas.

Determinación de las situaciones específicas de trabajo

La primera actividad del proyecto consistió en identificar los usos de agua realizados por las comunidades indígenas, susceptibles de ser regularizados. En el fondo, se debían determinar los derechos de agua de propiedad ancestral de estas comunidades, teniendo en cuenta los tres elementos básicos que vimos en el capítulo anterior: que recaigan en aguas que se encuentren dentro del hábitat ancestral de la comunidad; que sean usos antiguos, y que los realice la comunidad, en forma colectiva.

Sobrepasaría las pretensiones de este trabajo mencionar todas las aguas que fueron identificadas y medidas por el proyecto, como también aquellas que no lo fueron por distintas razones. No obstante, resulta oportuno mencionar los factores que determinaron que las fuentes identificadas y medidas fueran solicitadas a favor de una o de otra comunidad indígena, ya que este asunto tiene indudable interés para el estudio de estas agrupaciones étnicas. 
En efecto, en la perspectiva de solicitar la regularización a favor de los verdaderos usuarios de las aguas, pudimos constatar cómo el derecho consuetudinario de las comunidades atacameñas ha establecido con toda claridad quienes tienen derecho a usar determinadas fuentes, de tal manera que la regularización se solicitó a favor de estos usuarios.

Pues bien, en la zona atacameña el derecho consuetudinario indígena regula la asignación del recurso hídrico, pudiendo distinguirse, básicamente, dos clases de normas consuetudinarias que se encargan de ello: por un lado, aquellas normas que determinan la asignación de las aguas entre las propias comunidades y, por otro, aquellas que regulan el acceso a las aguas en el seno de cada comunidad.

a) Normas consuetudinarias entre comunidades indigenas. Son las propias comunidades las que han generado las normas que asignan entre ellas el uso de las aguas, reconociéndose todas mutuamente el derecho a utilizar determinadas fuentes y a construir las respectivas obras de captación.

Por regla general, cada comunidad tiene derecho a usar en forma exclusiva una o más fuentes de agua, como sucede con la comunidad de Toconce y el río Toconce; con la comunidad de Caspana y las vertientes Coller, Cablor y Chica; ${ }^{6}$ con la comunidad de Ayquina y las vertientes Kolo, Yauquén, Koyna y Kiruna, entre otras; con la comunidad de Talabre y las vertientes de Saltar; con la comunidad de Peine y el río Tulán; entre muchos otros casos.

La regularización de estas aguas, consiguientemente, fue solicitada exclusivamente por la respectiva comunidad indígena.

Ahora bien, existen dos excepciones a la regla indicada, en las que no existe uso exclusivo por una comunidad, sino que dos de éstas utilizan conjuntamente las aguas del mismo cauce:

- Cuando dos comunidades usan conjuntamente una misma fuente mediante las mismas obras, como ocurre con las comunidades de Ayquina y

6 No se solicitó la regularización de estas vertientes, ya que con anteridad al proyecto un grupo de agricultores de Caspana, encabezados por don Luis Colamar, regularizó sus derechos de ellas, según sentencia del $2^{\circ}$ Juzgado de Calama, causa Rol $\mathrm{N}^{\circ} 23.205$, inscrita de Fs. $1 \mathrm{~N}^{\circ} 1$ del Registro de Aguas de 1985 del C.B.R. de Calama. de Cupo en las vertientes Panire y Socavón de Panire.

En este caso, ambas comunidades solicitaron en conjunto la regularización.

- Cuando dos comunidades usan el mismo río, pero en diferentes sectores y a través de distintas obras de captación, como sucede con Lasana y ChiuChiu en el río Loa; ${ }^{7}$ y con Río Grande y San Pedro de Atacama en el río San Pedro y sus afluentes.

En este último caso, las aguas fueron solicitadas en conjunto por la comunidad de Río Grande y los regantes de San Pedro de Atacama.

b) Normas consuetudinarias al interior de cada comunidad. Dentro de cada comunidad, son sus propios miembros quienes crean las normas que regulan la asignación de las aguas entre ellos.

Por regla general, todo comunero tiene derecho a usar las aguas, con arreglo a los reglamentos que se discuten y establecen en la Asamblea Comunal (Castro y Martínez 1996: 79). Ello ocurre, por ejemplo, con la comunidad de Toconce y el río Toconce; con la cumunidad de Cupo y la vertiente Cupo; con la comunidad de Camar y las vertientes Camar, Pepina, Corcarte y Turbaca; con la comunidad de Socaire y el río Socaire; y así en casi todas las oportunidades.

En estos casos, la peticionaria de la regularización fue la respectiva comunidad indígena.

Sin embargo, esta regla admite dos excepciones:

- Cuando la comunidad reconoce que sólo un grupo de comuneros tiene derecho a usar las aguas de cierta vertiente, como ocurre en Toconao con las vertientes Zapar, Celeste, Aguas Blancas y Soncor; y en Talabre con la vertiente Patos.

En estos casos la regularización se solicitó a nombre de una asociación indígena, especialmente constituida al efecto, que agrupa exclusivamente a los respectivos usuarios.

- Cuando la comunidad indígena se ha desenten-

7 No se solicitó la regularización de estas aguas, por cuanto en ellas la DGA constituyó comunidades de agua, regidas por el Código de Aguas, el año 1984. 
dido de la administración de las aguas, derivando esta función a una organización de usuarios integrada exclusivamente por comuneros que poseen tierras agrícolas, llamados genéricamente "regantes". Esto sucede en San Pedro de Atacama con los ríos San Pedro y Vilama, y en Toconao con las aguas de la Quebrada de Jere.

Aquí también se solicitó la regularización a nombre de una asociación indígena, especialmente constituida al efecto, que agrupa exclusivamente a los respectivos "regantes".

Finalmente, cabe consignar que en cualquiera de las situaciones planteadas, es decir, sea que las aguas hayan sido asignadas a la comunidad indígena propiamente tal, o sólo a un grupo de comuneros o a una organización de regantes, su administración es eminentemente colectivista o comunitaria.

Por ejemplo, todos los usuarios tienen la obligación de participar, en igualdad de condiciones, en los trabajos colectivos de construcción y mantención de las obras comunes. Cada uno de ellos tiene derecho a una cuota de agua en proporción a la superficie de tierra que cultiva, la que se asigna mediante un sofisticado sistema de turnos o rateo. ${ }^{8}$ Todos tienen el mismo derecho a voz y voto en las asambleas, sin importar el volumen de agua que le corresponda. $Y$ en fin, todos eligen democráticamente a sus dirigentes --celadores, jueces de aguas, puricamanes, etc.-- encargados de organizar los trabajos colectivos, repartir las aguas, cobrar cuotas y aplicar sanciones.

Fundamentos legales de las solicitudes de regularización

Cuando iniciamos el estudio de las normas legales vigentes con el objeto de hilvanar la fundamentación jurídica de las solicitudes de regularización, concebimos que la Ley $\mathrm{N}^{\circ} 19.253$, el Art. $2^{\circ}$ transitorio del Código de Aguas y el Art. $7^{\circ}$ del D.L. 2.603, nos aportaban los instrumentos idóneos para tal propósito.

Por de pronto, la Ley $N^{\circ} 19.253$ reconoce la existencia de las comunidades atacameñas como una entidad histórico-sociológica que se remonta inclu-

8 Por ejemplo, hoy en San Pedro de Atacama se asigna dos horas de agua por cada hectárea. so a tiempos precolombinos, independientemente de su constitución legal. La misma ley reconoce la existencia de derechos de agua de propiedad ancestral de estas comunidades, y los ordena proteger, constituir e, incluso, restablecer.

La razón de este reconocimiento es el uso consuetudinario de las aguas hecho por las comunidades atacameñas, situación de conocimiento público y que se demuestra además con las obras construidas en torno a los cauces. A su turno, como las comunidades hoy también usan el recurso, las favorece la presunción legal de dominio del Art. $7^{\circ}$ del D.L. 2603 , que reputa dueño del derecho de aprovechamiento a quien actualmente se encuentre haciendo uso efectivo de las aguas.

Finalmente, dado que el uso de las aguas se ha realizado en forma ininterrumpida, libre de violencia y clandestinidad y sin reconocer dominio ajeno, desde tiempos "ancestrales", es perfectamente procedente que las comunidades regularicen sus derechos, de acuerdo con el Art. $2^{\circ}$ transitorio del Código de Aguas.

Con esta línea de razonamiento planteamos las solicitudes de regularización y orientamos la prueba en los juicios correspondientes. Nuestros argumentos fueron aceptados por la DGA y acogidos por el Juzgado de Letras, por la Corte de Apelaciones de Antofagasta e, incluso, por la Corte Suprema: ${ }^{9}$ los resultados están a la vista.

Sin embargo, no podemos negar que en ese entonces no teníamos ninguna seguridad que nuestros razonamientos serían aceptados por los tribunales, ya que no conocíamos otras experiencias de regularización de derechos de agua a favor de comunidades indígenas, ni tampoco sabíamos que esta materia hubiese sido tratada por la doctrina.

Por ello, no dejamos de sorprendernos positivamente cuando tiempo después conocimos el trabajo del profesor Alejandro Vergara Blanco (1998), quien elaboró un acabado estudio de los derechos de agua consuetudinarios o usos legítimos de agua reconocidos como derechos por la ley, que estimamos perfectamente concordante con nuestra línea de argu-

9 Regularización de los ríos Quepiaco y Alitar, comuna de San Pedro de Atacama, a favor de la Comunidad Atacameña de Toconao. 
mentación y que, unido a los fallos favorables que obtuvimos, viene a confirmar la legitimidad de los procesos de regularización en estudio.

Resultados del proyecto

Los resultados concretos del proyecto fueron, en síntesis, los siguientes:

Ubicación y medición de 85 fuentes de agua. Se practicaron tres rondas de aforos en 85 fuentes de agua, distribuidas en las comunas de Ollagüe, Calama y San Pedro de Atacama, durante tres meses consecutivos a partir de febrero de 1995. En estas rondas se determinaron además las coordenadas UTM y la cota de todos los puntos de captación, mediante GPS, corroborándose después esta información en la cartografía del Instituto Geográfico Militar (I.G.M.), escala 1:50.000.

Constitución de 18 organizaciones indígenas. Se formaron legalmente 18 organizaciones indígenas, 11 comunidades y siete asociaciones de regantes, con el objeto de hacer a nombre de ellas las respectivas solicitudes. De esta manera, quedaron constituidas de acuerdo a la Ley $\mathrm{N}^{\circ} 19.253$, todas las comunidades atacameñas de la II Región, además de la única comunidad quechua existente en el país.

Regularización de 70 derechos por $2.278,8 \mathrm{l} / \mathrm{s}$. Se tramitaron íntegramente 18 procesos de regularización, culminado con la inscripción de 70 derechos de agua, todos consuntivos, permanentes y continuos, por un caudal de $2,278,8$ litros por segundo. ${ }^{10}$

Expondremos a continuación todos los casos regularizados en virtud del proyecto, que representan a lo menos el $85 \%$ de las aguas usadas por las comunidades indígenas de la Provincia de El Loa. En cada caso, se indica; el titular del derecho, el rol de la causa; los opositores, en su caso; la fecha de la sentencia; la inscripción conservatoria; y el nombre y

10 Los casos que quedaron pendientes del proyecto, atendida la oposición de terceros o su especial complejidad, fueron únicamente los siguientes: 1) Vertiente Amincha a favor de la Comunidad Quechua de Ollagüe; 2) Río Toconce a favor de la Comunidad Atacameña de Toconce; 3) Vertiente Turi, a favor de la Comunidad atacameña de Ayquina-Turi; y, 4) Vertiente Patos, a favor de un grupo de regantes de Talabre. Estos casos se encuentran actualmente en proceso de regularización, en virtud de posteriores proyectos de CONADI. caudal de cada fuente.

Cabe consignar que todos los casos que se mencionan tienen en común los siguientes antecedentes:

Tribunal: Segundo Juzgado de Letras en lo Civil de El Loa-Calama.

Inscripción: Registro de Aguas del Conservador de Bienes Raíces de El Loa Calama.

Naturaleza de las aguas: Superficiales ${ }^{11}$ y corrientes.

Tipo de derechos: Consuntivos, permanentes y continuos.

Comuna de Ollagüe

Caso 1

Titular: Comunidad Quechua de Ollagüe

Rol: $4059-96$

Opositores: Ferrocarril de Antofagasta a Bolivia

Sentencia: 01.06 .99

Inscripción: Fs. $46 \mathrm{~N}^{\circ} 45$ año 1999

Cauces

Caudal (1/s)

$\begin{array}{ll}\text { Vert. del Inca } & 1 \\ \text { Vert. Cohasa } & 1 \\ \text { Vert. Coska } & 3 \\ \text { Vert. Carcote } & 1 \\ \text { Vert. Alconcha } & 1 \\ \text { Vert. Cuchicha } & 5 \\ \text { Vert. Ojo Caliente } & 1 \\ \text { Vert. Sapunta } & 3 \\ \text { Río Chela } & 7 \\ \text { Río Chaihuiri } & 4 \\ \text { Río Casicsa } & 1 \\ \text { Río Blanco } & 1\end{array}$

Total derechos: 12

Total caudal (l/s): 29

Comuna de Calama

Caso 2

Titular: Comunidad Atacameña de Ayquina-Turi Rol: $4052-96$

11 El único caso de aguas subterráneas es el del Pozo 5, regularizadas por la Comunidad Atacameña de Solor. 
Sentencia: 15.04 .97

Inscripción: Fs. 71 Nº 61 año 1997

Cauces

Caudal $(L / s)$

Vert. San Isidro

5,5

Vert. Koyer

Vert. Kolo

3

2,6

Vert. Yauquén $\quad 0,2$

Vert. Arcipe $\quad 4,6$

Vert. Chañaral $\quad 7,2$

Vert. Taka-Taka 12

Vert. Koyna $\quad 5,1$

Vert. Kiruna $\quad 3,7$

Vert. Chiber $1 \quad 1,4$

Vert. Chiber $2 \quad 0,1$

Vert. La Punta 0,1

Vert. El Medio $\quad 0,1$

Vert. Lukcher $\quad 0,1$

Total derechos: 14

Total caudal $(1 / \mathrm{s}): 45,7$

Caso 3

Titular: Comunidad Atacameña de Ayquina-Turi y

Comunidad Atacameña de Cupo

Rol: 4053-96

Sentencia: 15.04 .97

Inscripción: Fs. 90 No 67 año 1997

Cauces $\quad$ Caudal $(1 / \mathrm{s})$

Vert. Panire

1,1

Vert. Socabón

2,8

Total derechos: 2

Total caudal $(1 / \mathrm{s}): 3,9$

Caso 4

Titular: Comunidad Atacameña de Cupo

Rol: 4056-96

Sentencia: 15.04 .97

Inscripción: Fs. 68 Nº 60 año 1997

Cauces

Caudal $(l / s)$

Vert. Cupo

10,2

Vert. Cupo (camino)

6,8

Total derechos: 2
Total caudal (l/s): 17

Caso 5

Titular: Comunidad Atacameña de Conchi Viejo

Rol: 4055-96

Sentencia: 16.04 .97

Inscripción: Fs. $84 \mathrm{~N}^{\circ} 65$ año 1997

Cauces Caudal $(V / s)$

Vert. Conchi Viejo $\quad 0,3$

Total derechos: 1

Total caudal ( $1 / \mathrm{s}): 0,3$

Comuna de San Pedro de Atacama

Caso 6

Titular: Comunidad Atacameña de Río Grande y Asociación Atacameña de Regantes y Agricultores de San Pedro de Atacama

Rol: 4057-96

Opositores: Ana María Barón Parra, Tulor S.A., Juan D'Etigny Lira y Explora S.A.

Sentencias: $26.11 .97,1^{\circ}$ Instancia; 14.11 .98 , Casación Corte de Apelaciones de Antofagasta; y, $01.06 .99,1^{\circ}$ Instancia.

Inscripción: Fs. $45 \mathrm{~N}^{\circ} 46$ año 1999

Cauces

Caudal $(1 / s)$

$\begin{array}{ll}\text { Río San Pedro } & 870 \\ \text { Río Grande } & 125 \\ \text { Río Salado } & 17 \\ \text { Río Putana } & 10 \\ \text { Río Jauna } & 99 \\ \text { Río Incahuasi } & 10 \\ \text { Río Tocorpuri } & 10 \\ \text { Vert. Yerbas Buenas } & 8 \\ \text { Vert. Felon } & 3 \\ \text { Vert. Guaitiquina } & 3 \\ \text { Vert. Vega Paila } & 2 \\ & \\ \text { Total derechos: } 11 & \\ \text { Total caudal (1/s): } 1.157 & \\ & \\ \text { Caso 7 } & \\ \text { Titular: Comunidad Atacameña de Machuca } \\ \text { Rol: } 4054-96 \\ \text { Sentencia: } 30.05 .97\end{array}$




\section{Cauces}

Caudal $(l / s)$

10

Río Machuca

Vert. Turipite

Río Alitar 130

Río Quepiaco

200

Total derechos: 2

Total caudal (1/s): 330

Total derechos: 2

Total caudal (1/s): 13,8

Caso 8

Titular: Asociación Atacameña de Regantes y Agricultores del Río Vilama

Rol: 4061-96

Opositores: Explora S.A.

Sentencia: 30.05 .97

Inscripción: Fs. $105 \mathrm{~N}^{\circ} 72$ año 1997

Cauces

Caudal $(l / s)$

Río Vilama

180

Río Puritama (Baños)

10

Río Puritama (Guatín)

21

Río Purifica

10

Total derechos: 4

Total caudal (1/s): 221

Caso 9

Titular: Comunidad Atacameña de Sólor

Rol: 4065-96

Sentencias: 30.05 .97

Inscripción: Fs. 96 Nº 69 año 1997

Cauces Caudal $\left(l_{s}\right)$

Pozo 5

\section{1,5}

Total derechos: 1

Total caudal (l/s): 1,5

Caso 10

Titular: Comunidad Atacameña de Toconao

Rol: 4066-96

Opositores: Mario Schellman Ballaco

Sentencias: $30.05 .97,1^{\circ}$ Instancia; $31.10 .97,2^{\circ}$ Instancia; y 31.03.98, Casación Corte Suprema.

Inscripción: Fs. $44 \mathrm{~N}^{\circ} 41$ año 1998

\section{Caso 11}

Titular: Asociación Atacameña de Regantes y Agricultores de Toconao

Rol: 4069-96

Opositores: Explora S.A.

Sentencia: 25.11 .97

Inscripción: Fs. $7 \mathrm{~N}^{\circ} 7$ año 1998

Cauces

Caudal (1/s)

Río Toconao (Jere) 60

Total derechos: 1

Total caudal (1/s): 60

Caso 12

Titular: Asociación Atacameña de Regantes y Agricultores de Celeste

Rol: 4060-96

Sentencia: 15.04 .97

Inscripción: Fs. $81 \mathrm{~N}^{\circ} 64$ año 1997

Cauces

Caudal $(l / s)$

Vert. Celeste

4

Total derechos: 1

Total caudal (1/s): 4

\section{.Caso 13}

Titular: Asociación Atacameña de Regantes y Agricultores de Aguas Blancas

Rol: 4062-96

Sentencia: 30.05 .97

Inscripción: Fs. $78 \mathrm{~N}^{\circ} 63$ año 1997

Cauces

Caudal $(/ / s)$

Vert. Aguas Blancas

110

Total derechos: 1 
Total caudal (l/s): 110

\section{Caso 14}

Titular: Asociación Atacameña de Regantes y Agricultores de Soncor

Rol: 4063-96

Sentencia: 15.0497

Inscripción: Fs. 75 N 62 año 1997

Cauces $\quad$ Caudal $(l / s)$

Vert. Soncor

Total derechos: 1

Total caudal (l/s): 12,3

Caso 15

Titular: Comunidad Atacameña de Talabre

Rol: 4086-96

Sentencia: 16.04 .97

Inscripción: Fs. $99 \mathrm{~N}^{\circ} 70$ año 1997

Cauces

Caudal $(/ / s)$

Vert. Talabre

Vert. Catarape

Vert. Saltar 1

4,3

Vert. Saltar 2

18,5

Total derechos: 4

Total caudal (l/s): 46,3

Caso 16

Titular: Comunidad Atacameña de Camar

Rol: 4058-96

Opositores: Explora S.A.

Sentencia: 04.12.97

Inscripción: Fs. $5 \mathrm{~N}^{\circ} 5$ año 1998

Cauces Caudal (1/s)

Vert. Camar 1

3,2

Vert. Camar 2

10,4

Vert. Pepina

2,7

Vert. Corcacte

3,4

Vert. Turbaca

6,9

Total derechos: 5

Total caudal (1/s): 26,6

\section{Caso 17}

Titular: Comunidad Atacameña de Socaire

Rol: 4068-96

Sentencia: 16.04 .97

Inscripción: Fs. $93 \mathrm{~N}^{\circ} 68$ año 1997

Cauces

Caudal $(l / s)$

Río Socaire

130

Vert. Quepe

5

Total derechos: 2

Total caudal (l/s): 135

Caso 18

Titular: Comunidad Atacameña de Peine Rol: 4067-96

Sentencia: 15.04 .97

Inscripción: Fs. 87 Nº6 año 1997

Cauces

Caudal $(l / s)$

$\begin{array}{ll}\text { Vert. Ossa y Vilte } & 18,6 \\ \text { Vert. Tarajne } & 1,7 \\ \text { Vert. Chaquisoqui } & 2,3 \\ \text { Río Tulán } & 43\end{array}$

Total derechos: 4

Total caudal (1/s): 65,6

Totales

Procesos tramitados: 18

Organizaciones beneficiadas: 18

Derechos inscritos: 70

Caudal inscrito: $2.278,8 \mathrm{l} / \mathrm{s}$

\section{Conclusiones}

La pérdida de las aguas de las comunidades aymaras $y$ atacameñas del norte de Chile, es una consecuencia de la desprotección jurídica en que éstas quedaron a raíz de la subordinación del derecho indígena al derecho positivo estatal. Desde los albores del siglo XX la autoridad privilegió el desarrollo minero y urbano de la zona, aún a costa de la sobrevivencia de las comunidades agrarias y rurales de los Andes, quienes por no contar con títulos o concesiones para usar las aguas, fueron considera- 
das simples usuarias, de facto y sin derechos.

Esta situación cambió, de alguna manera, con el reconocimiento otorgado por la Ley Indígena de 1993 a los derechos de agua de propiedad ancestral de las citadas comunidades. El legislador, en suma, legitimó sus usos consuetudinarios de aguas --los reconoció como derechos--, permitiendo su posterior regularización.

El rasgo más trascendental de estos derechos es su calidad de "comunitarios" o "colectivos", ya que a consecuencia de ello la ley abrió en el seno de cada comunidad un espacio para la vigencia de la costumbre indígena como fuente del derecho. En efecto, como las dueñas de los derechos son las comunidades y no sus miembros, al interior de cada una de ellas no se aplican las normas del Código de Aguas, que regulan las relaciones entre titulares de derechos, sino que tienen plena validez las normas consuetudinarias que la propia comunidad ha creado y que va reelaborando constantemente. ${ }^{12}$

Como resultado de este proyecto, fueron reconocidos judicialmente e inscritos en el registro conservatorio la gran mayoría de los derechos de agua de propiedad ancestral de las comunidades atacameñas (70 derechos a favor de 18 organizaciones indígenas, por un caudal total de $2.278,8 \mathrm{1} / \mathrm{s}$ ), lo que cons- tituye un paso de trascendental importancia en la protección de esta etnia y la base en la que podrá sustentarse su anhelado desarrollo.

Sin embargo, la tarea de amparar estos derechos y usos consuetudinarios de agua, está muy lejos de haber concluído. En los últimos años se han planteado nuevas situaciones que amenazan el legítimo ejercicio de los mismos, debido de la fuerte presión de las empresas mineras por extraer las aguas subterráneas del territorio atacameño.

Este fenómeno, además de causar impactos muy negativos en la preservación de los ecosistemas andinos, afecta directamente a las comunidades indígenas: está provocando la desecación de diversas vegas de uso ganadero y pastoril, y en ciertos casos ha hecho mermar el caudal de las aguas superficiales, de uso agrícola, que se abastecen con aportes subterráneos.

Enfrentar estos problemas es el desafío que hoy deben asumir las comunidades indígenas y todos los que deseamos que éstas y su cultura sigan presentes en el árido y vasto desierto de Atacama.

San Pedro de Atacama, marzo de 2001.

12 Ver nota 5

\section{BIBLIOGRAFIA}

AGURTO P., 1986. Inscripción y regularización de derechos de aprovechamiento de aguas. Aplicación práctica de los arts. $1^{\circ}$ y $2^{\circ}$ transitorios del Código de Aguas. Convención de Nacional de Regantes de Chile, Santiago 29 y 30 de agosto de 1986, Confederación de Canalistas de Chile.

ALDUNATE, C., 1985 La desecación de las vegas de Turi. Chungará 14: 135-140, Arica.

BARRIENTOS, J. y A. DOUGNAC, 1993. Jurisprudencia Indiana sobre el Derecho de Aguas, I: Turnos, Revista de Derecho de Agulas vol. IV: 127-153, Instituto de Derecho de Minas y Aguas, Universidad de Atacama.

CASTRO. M.. 1997. Agua, derechos y cultura en los Andes del norte de Chile. Un enfoque desde la antropología juridica. Chungará vol. 29 (1): 63-80.

CASTRO, V. y J. MARTINEZ, 1996. Poblaciones indígenas de Atacama. Etnografía: Sociedades indígenas contemporáneas y su ideología. Editorial Andrés Bello. Santiago.
CUNEO VIDAL, R., 1977. Obras Completas, Historia de la civilización peruana, Tomo I, Ignacio Prado Pastor, (Ed.) Lima, Perú.

DESMARCHELIER, C., 1998. El hombre andino y su relación con el medio ambiente. Revista Prisma 1, página web http:/ /rehue.csociales.uchile.cl/rehuehome/facultad/publicaciones/ prisma/prisma1/andes.htm, Facultad de Ciencias Sociales, Universidad de Chile.

DOUGNAC, F. 1975. La legislación aplicable a los indígenas del norte de Chile. Revista Norte Grande, vol. I, números (3-4): 139-140, Universidad Católica de Chile.

ESCALANTE. P. M.. 1992 Ms. Minuta sobre Regularización de Derechos de Agua.

MATUS DE LA P., A., 1993-1994. El ceremonial de la limpia de canales en Caspana. Revista Chilena de Antropología, 12: 65-86, Universidad de Chile. 
NUÑEZ A., L., 1992. Cultura y conflicto en los oasis de San Pedro de Atacama. Editorial Universitaria, Santiago.

NUÑEZ H., P., 1990. Sistema hidráulico en la agricultura andina. Desarrollo Andino y Cultura Aymara en el Norte de Chile. Taller de Estudios Andinos, Ediciones Jote Errante.

---- 1991. Sobre economía prehispánica de Socaire, norte de Chile. Actas del XI Congreso de Nacional de Arqueología Chilena. T II: 201-210, Museo Nacional de Historia Natural y Sociedad Chilena de Arqueología, Santiago.

POURRUT, P. y L. NUÑEZ, 1995. (Eds.) Agua, ocupación del espacio y economía campesina en la región atacameña, as pectos dinámicos. Universidad Católica del Norte, Antofagasta.

RAMIREZ, D., 1995. Régimen legal de las aguas del Valle de Azapa. Revista de Derecho de Aguas vol. VI: 57-128, Instituto de Derecho de Minas y Aguas, Universidad de Atacama.

VERGARA A., 1997. El mercado de derecho de aguas, Colegio de Abogados de Chile A.G.

... 1998. Derecho de Aguas, Editorial Jurídica de Chile, Santiago. 